\title{
EDITORIAL
}

\section{SNARE PROTEINS AS MOLECULAR MASTERS OF INTERNEURONAL COMMUNICATION}

\author{
Danko D. Georgiev ${ }^{1}$ and James F. Glazebrook ${ }^{2}$ \\ ${ }^{1}$ Department of Psychiatry and Neurobiology, Graduate School of Medical Science, Kanazawa \\ University, Kanazawa, Ishikawa, Japan and ${ }^{2}$ Department of Mathematics and Computer Science, Eastern \\ Illinois University, Charleston IL, USA
}

\section{THE NEURON DOCTRINE}

In the beginning of the $20^{\text {th }}$ century the groundbreaking work of Ramon y Cajal firmly established the neuron doctrine, according to which neurons are the basic structural and functional units of the nervous system $(1,2)$. Von Weldeyer coined the term "neuron" in 1891 (3), but the huge leap forward in neuroscience was due to Cajal's meticulous microscopic observations of brain sections stained with an improved version of Golgi's la reazione nera (black reaction). The latter improvement of Golgi's technique made it possible to visualize the arborizations of single neurons that were "colored brownish black even to their finest branchlets, standing out with unsurpassable clarity upon a transparent yellow background. All was sharp as a sketch with Chinese ink" (4). The high quality of both the visualization of individual nerve cells and the work performed on studying the anatomy of the central nervous system lead Ramon y Cajal to the conclusion that axons output the nervous impulses to the dendrites or the soma of other target neurons. The name "dendrite" was coined by His in 1889 (5) and "axon" by von Kölliker in 1896 (6), but it was Ramon y Cajal who developed and provided extensive anatomical evidence for the idea that neurons are dynamically polarized and within each neuron the transmission of information is from the dendrites towards the axon (2). Based upon numerous observations, Ramon y Cajal concluded that neurons are indeed individual cells, which should transmit information between each other at the places of contact and that neuronal somata do not only have trophic function but also participate in the conduction of the neuronal impulses. Further, he argued that the exclusion of substantial continuity between cell and cell leaves open the hypothesis that the nervous impulse is transmitted by contact, as in the articulations of electrical conductors, or by a kind of induction, as with induction coils (4). The 1906 Nobel Prize in Physiology or Medicine was awarded jointly to Ramon y Cajal and Camillo Golgi for the development of the silver nitrate impregnation technique $(2,7)$. Surprisingly, Golgi still believing that the nervous system was a reticulum, or a connected meshwork, rather than a system made up of discrete cells, delivered his acceptance speech as a sustained attack on the neuron doctrine (7)

Received 23 December 2010, accepted 28 December 2010

Correspondence: Dr Danko D. Georgiev, Department of Psychiatry and Neurobiology, Graduate School of Medical Science, Kanazawa University, 13-1 Takaramachi, Kanazawa, Ishikawa 920-8641, Japan. E-mail: danko@med.kanazawa-u.ac.jp 
One of the reasons for Golgi's disbelief in the neuron doctrine was due to the fact that there was no direct evidence of interneuronal discontinuous articulations or "synapses", a term introduced in 1897 by Charles Sherrington (8). The "synapse" (Fig. 1) was identified only with the advent of the electron microscope when "synaptic vesicles" were observed for the first time by George E. Palade and others $(9,10)$. In 1956, Palay conjectured that the synaptic vesicles might contain chemical neurotransmitters such as acetylcholine, the release of which is responsible for the transmission of the nervous impulse to the postsynaptic neuron (11).

At the same time, Sir John Eccles and other electrophysiologists were successfully unraveling the mysteries of neurotransmitter action at the postsynaptic site $(13,14)$. Thus Cajal's idea of synaptic transmission as analogous to the electromagnetic processes occurring in "induction coils" has been shown to be wrong and replaced by chemical release and chemical interaction with postsynaptic receptors. The importance of these new findings was soon officially recognized. Eccles received the 1963 Nobel Prize in Physiology or Medicine for his research concerning the ionic mechanisms involved in excitation and inhibition in the peripheral and central portions of the nerve cell membrane (15), and Palade, together with Albert Claude and Christian de Duve, received the 1974 Nobel Prize in Physiology or Medicine for their discoveries concerning the structural and functional organization of the cell (16).

The neuron doctrine seemed to be victorious at last the neurons are individual cells communicating at specialized intercellular junctions called "synapses" via release of chemical substances collectively known as "neurotransmitters" through exocytosis of synaptic vesicles. Since the release of neurotransmitter occurred only in discrete portions called "quanta", it was not hard to further conjecture that a

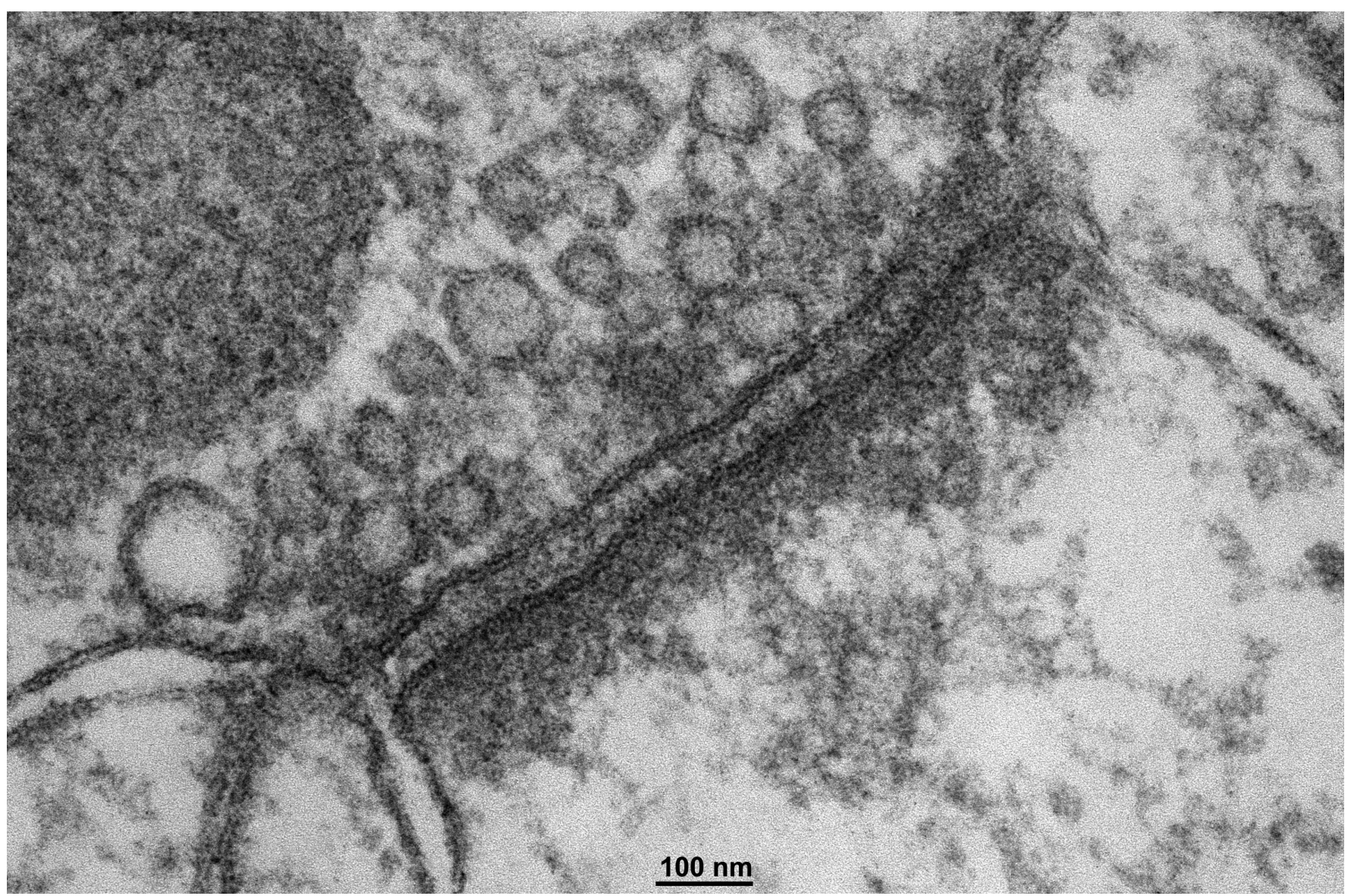

Figure 1. Neurotransmitter vesicles in a synapse of rat cerebral cortex. One of the vesicles is docked to the presynaptic membrane apparently in a "primed" state ready to release its contents upon $\mathrm{Ca}^{2+}$ triggering. The synaptic cleft and the postsynaptic space are filled with electron dense material, which indicates the abundant presence of cell adhesion molecules and postsynaptic density scaffold proteins. Image kindly provided by Holger Jastrow (12). 
single "quantum" corresponds to the neurotransmitter content within one synaptic vesicle. The discovery of the quantal mechanism of neurotransmitter release lead to another Nobel Prize in Physiology or Medicine, which was awarded to Katz in 1970 (17).

After such a wide recognition of the neuron doctrine it is surprising that there could be anything unsettling with it. Several problems, however, arose from the philosophical queries into the nature of human mind (consciousness). We all are well aware of the fact that a healthy human subject feels as a single mind united in its experience. When we watch a movie for example we hear the sound, see the images and even feel the thrill in our body, all of which happens at once with the different experiences bound into a synchronous union. There are no separate minds: one that sees, one that hears or one that feels the somatosensory inputs. Instead there is only one single mind that sees, hears and feels. In philosophy, neurosciences and anesthesiology this became to be known as the cognitive binding problem (18). If the brain is composed of separate individual entities called neurons, what is the "glue" that binds the conscious experience together?

One of the most provocative theories that addresses how the mind could be "glued" together came from Eccles and Beck in $1992(19,20)$. The authors proposed a dualistic model using quantum theory in physics. The cerebral cortex is composed of cerebral columns of vertically interconnected neurons called "dendrons" and with each cerebral column was postulated an associated mental unit called a "psychon". The role of each psychon was to control the synaptic vesicle release within the synapses of the associated dendron through a quantum processes called "tunneling". At the time relatively little was known about the molecules involved in neurotransmitter release, and it was erroneously postulated that the synaptic vesicle fusion required the tunneling of electrons between the lipid membrane of the synaptic vesicle and the presynaptic plasma membrane (19).

\section{THE SNARE PROTEINS}

With the flourishing of molecular biology in 1990's the focus was gradually shifted towards the molecular masters controlling the synaptic vesicle exocytosis, the so-called SNARE proteins [an acronym derived from Soluble NSF (N-ethylmaleimide Sensitive Fusion protein) Attachment Protein Receptor] and the Beck-Eccles hypothesis remained in the "backwaters" of neuroscience.

In general terms, SNAREs comprise distinct families of conserved membrane-associated proteins, which facilitate membrane fusion in eukaryotes. SNAREs present on the vesicle (or donor) compartment are known as v-SNAREs, while those on target (or acceptor) compartment are known as tSNAREs. The SNARE proteins are divided into three major families: the syntaxin, SNAP-25 and VAMP/synaptobrevin families (21). In the synapse, VAMP/synaptobrevin proteins are present in the synaptic vesicles, while syntaxin and SNAP-25 reside in the presynaptic membrane (Fig. 2). The zipping of $4 \alpha$-helices: one contributed by synaptobrevin, one by syntaxin and two by SNAP-25, creates a compressive force, which drives the fusion between the synaptic vesicle and the presynaptic plasma membrane (22). The interacting amino acid residues that zip the core SNARE complex can be grouped into layers. Each layer has 4 amino acid residues one residue per each of the $4 \alpha$-helices forming the bundle. In the center of the core complex is the "zero ionic layer" composed of one arginine $(\mathrm{R})$ and three glutamine $(\mathrm{Q})$ residues, and it is flanked by leucine zippering. The arginine is contributed by the v-SNARE synaptobrevin, while glutamines are contributed by the t-SNAREs syntaxin and SNAP-25. This lead to alternative (modern) classification of the SNARE proteins into R-SNAREs or Q-SNAREs proteins, which contribute respectively an arginine (R) or a glutamine $(\mathrm{Q})$ residue in the formation of the zero ionic layer in the assembled core SNARE complex (23).

In cells that undergo constitutive exocytosis, the SNARE proteins alone are sufficient to drive the vesicle fusion with the plasma membrane. In neurons, however, the excitationsecretion coupling is achieved by SNARE master proteins such as synaptotagmin (24-26). Synaptotagmin is a $\mathrm{Ca}^{2+}$ sensor that triggers exocytosis only if there is a presynaptic action potential, ensuring the transmission of the nervous signal towards the postsynaptic neuron or muscle cell. Furthermore, the different synaptotagmin isoforms might promote different modes of neurotransmitter release. The traditional view of this event is that given the opening of the fusion pore, the pore is dilated (Fig. 3) and the synaptic vesicle merges with the plasma membrane at the active zone. However, it is possible for the fusion pore to be transiently stabilized in order to release the neurotransmitter and then to rapidly terminate, the so-called "kiss-and-run" mode (27). The rise in presynaptic $\mathrm{Ca}^{2+}$ concentration could be observed with fluorescent dye methods using photo-sensitive $\mathrm{Ca}^{2+}$ binding compounds, while the neuro-secretion can be monitored either by an increase in membrane capacitance entailing a fusion of vesicles 

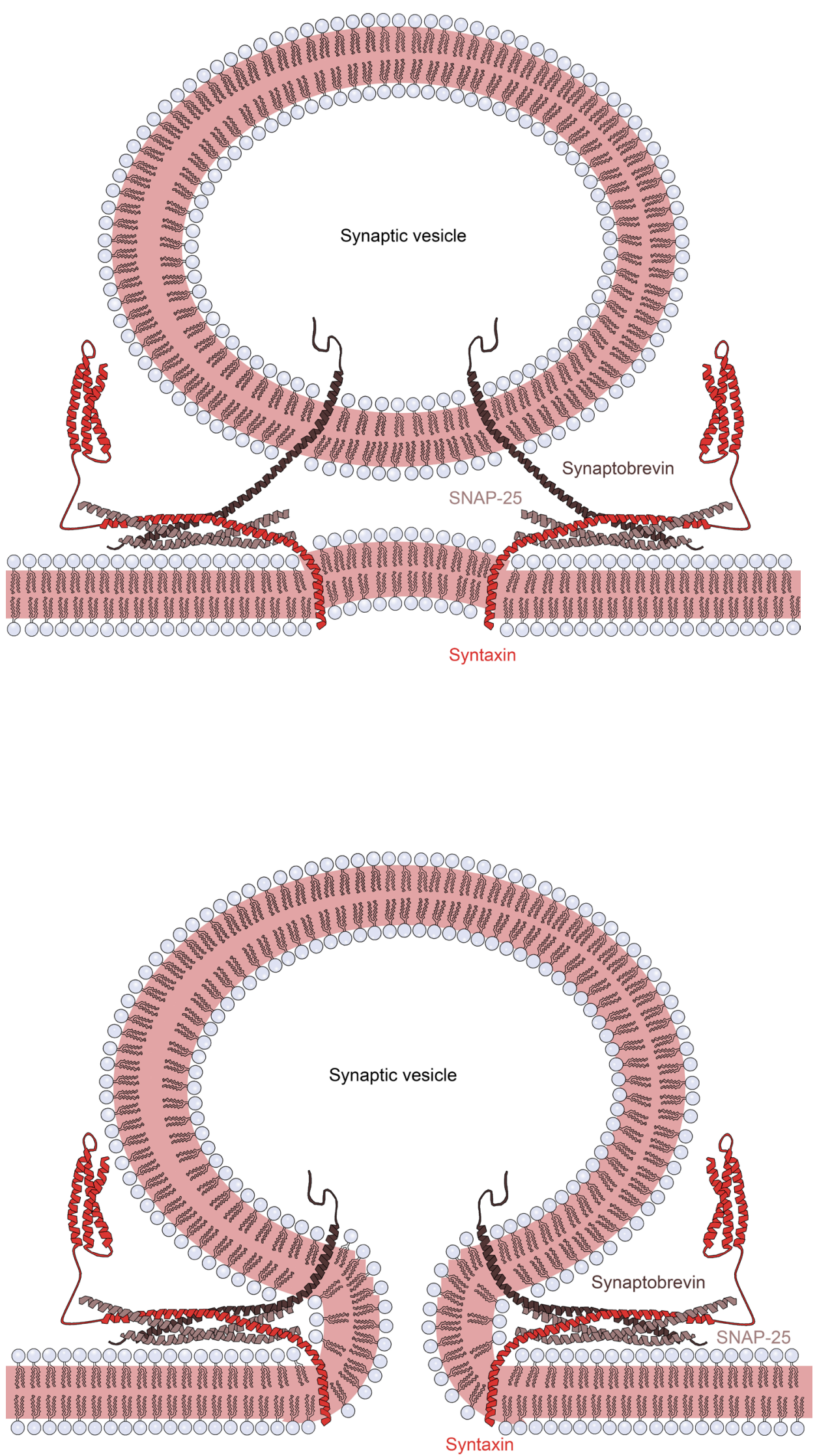

Figure 2. Docked synaptic vesicle in the presynaptic terminal of a neuron. Three different SNARE proteins interact with their $\alpha$-helices in order to form hemi-

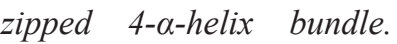
The SNARE proteins are important targets of volatile anesthetics, and at present the only gene mutation known to produce resistance to volatile anesthesia is in the syntaxin gene.

Figure 3. Opening and dilation of the fusion pore is driven by full zipping of the SNARE proteins. In the "kiss-and-run" mode of exocytosis the fusion pore closes before the synaptic vesicle is fused with the presynaptic membrane. Which factors could control such transient zipping and unzipping of SNARE 4-a-helix bundle is one of the important topics in the ongoing research. 
with the plasma membrane or microscopically with the use of various fluorescent dyes loaded into the synaptic vesicles (28). Molecular studies have revealed that synaptotagmin I is predominantly associated with the complete synaptic vesicle fusion, while synaptotagmin IV predominantly leads to "kiss-and-run" exocytosis (29). The latter secretion from small and medium-diameter vesicles and vesicle arrays without complete membrane fusion, is also known as "porocytosis" (30). A detailed review of the porosome structure and dynamics as revealed by atomic force microscopy is given by Jena in this volume (31). In his state-of-the-art exposition, Jena argues that complete vesicle fusion is a "terribly wasteful" process, which makes little biological sense. Indeed the cell might achieve better control of neurotransmitter release if it adjusts the "porosome" dynamics according to its needs, allowing for "single synaptic vesicles to fuse transiently and successively without loss of identity" (31).

Although the molecular function of the SNARE proteins fully deserves being called "extraordinary", it is not the only intriguing thing about SNAREs. Amazingly, the only known gene mutation that could produce resistance to volatile anesthesia is located in the syntaxin gene $(32,33)$, and it is known that volatile anesthetics can bind in the hydrophobic core of the SNARE 4- $\alpha$-helix bundle. Production of a truncated form of syntaxin could interfere with the binding of volatile anesthetics to the core SNARE complex, and this might explain the origin of the resistance to anesthesia. Since general anesthesia with clinical concentrations of volatile anesthetics inhibits neurotransmitter release (34) and selectively erases consciousness (but not all cortical responses, for example, evoked potentials can be recorded from visual cortex of anesthetized animal), there may appear to be some deep connection between the neuro-cognitive functional mechanism of SNAREs and that of the human mind.

The idea that the synaptic release of neurotransmitter is finely regulated by the presynaptic protein machinery is not new, and is a central theme of the Beck-Eccles hypothesis that was discussed earlier $(19,20)$. Regardless of the mode through which the exocytosis proceeds: full fusion or "kissand-run", it is well known that the probability of neurotransmitter release from a synaptic button upon the action potential is quite low, and for the central nervous synapse it might be in the range of 0.15 to 0.30 . This means that if an axon has 1000 terminals, on average only 300 of them will release the neurotransmitter and evoke postsynaptic responses per single action potential. The chance (or randomness) in in- terneuronal communication thus seems to be overwhelming. For example, there are $5 \times 10^{263}$ possible combinations for which 300 synapses out of 1000 are releasing neurotransmitters. Although most neuroscientists appeal to putative error correction codes in order to explain why the huge number of synaptic failures do not lead to havoc in the function of the neuronal networks, for those who are more philosophically oriented the existence of such randomness (indeterminism) is an opportunity to argue for the existence of human free will (19). If our mind is able to control the timing of exocytosis and the amount of various neurotransmitters in different regions of the brain, then we are simply not automata, and our conscious choices might have a real impact on brain dynamics. Although Beck and Eccles were off the track with their proposal of quantum tunneling of electrons between lipid membranes, for a modern molecular neuroscientist it is conceivable that the idea might work if it is properly adapted for SNARE proteins or other SNARE master proteins. Here we mention the role of two classes of molecules forming a cell adhesion system inside the synapse, $\beta$-neurexin (presynaptic) and neuroligin (postsynaptic) possessing a characteristic property that their interaction serves as a bidirectional trigger for synaptic formation. $\beta$-neurexin interacts presynaptically with CASK, a mutidomain scaffolding protein responsible for organizing presynaptic space, and with the aid of certain other proteins transmit signals into the actin cytoskeleton. $\beta$-neurexin also interacts with the synaptic vesicle protein synaptotagmin-1 and so influences the synaptic vesicle docking and the subsequent neurotransmitter release (35). Postsynaptically, neuroligin transmits information to postsynaptic density proteins such as PSD-95; however it may send also signals towards the presynaptic space through its interaction with $\beta$-neurexin. Alterations in the genetic encoding of neurexins and neuroligins have been implicated in the onset of several cognitive disorders (such as autism spectrum disorders) that may originate from subtle alterations in synaptic configurations as opposed to a wholesale demise in neural circuitry (36). As of now the full potential of their biomolecular properties has yet to be realized.

\section{SNARE FOR THOUGHT}

In this brief historical survey we have been reflecting upon three fundamental problems in contemporary cognitive neuroscience (and philosophy of mind) all of which require us to consider the function of SNARE proteins. First, neurons are anatomically segregated units, which however produce 
a single united experience (mind). In order to solve this discrepancy one must find a satisfying theory, which explains how the SNARE proteins control the release of neurotransmitters and interneuronal communication in such a manner that could ensure the cognitive binding. Secondly, one of the main effects of volatile anesthetics is to block the proper SNARE function and, conversely, the only known gene mutation, which leads to resistance to volatile anesthesia is found in the syntaxin gene. Thus consciousness, anesthesia (lack of consciousness) and SNARE function appear to be tightly connected, although at present we lack any satisfactory understanding. Last but not least, the large probability of synaptic failure found in central nervous synapses provides theorists with an opportunity to consider various options for subneuronal control of SNARE function in which the human mind could have a free will beyond the clockwork-like performance of a mechanical automaton. Our intention is not to provide ultimate answers to the various questions that have been raised, but to promote the reader's interest and show that even very specialized topics in molecular neuroscience could be brought to life if considered from the perspective of potential contribution to the theory of mind.

\section{REFERENCES}

1. Ramon y Cajal S. Textura del Sistema Nervioso del Hombre y de los Vertebrados. Imprenta y Librería de Nicolás Moya, Madrid, 1899. Texture of the Nervous System of Man and the Vertebrates. Edited by Pasik P, Pasik T. Springer, 2000.

2. Ramon y Cajal S. The structure and connexions of neurons. Nobel Lecture, December 12, 1906.

3. von Waldeyer W. Ueber einige neuere Forschungen im Gebiete der Anatomie des Centralnervensystems. Deutsche medicinische Wochenschrift, Berlin, 1891; 17: 1213-1218, 1244-1246, 1267-1269, 1287-1289, 13311332, 1352-1356.

4. Ramon y Cajal S. Recuerdos de mi vida, Imprenta y Librería de Nicolás Moya, Madrid, 1917. Recollections of my Life. Translated by E. H. Craigie \& J. Cano, MIT Press, 1989.

5. His W. Die Neuroblasten und deren Entstehung im embryonalen Mark. Abhandlungen der mathematisch-physischen Classe der Königlich Sächsischen Gesellschaft der Wissenschaften 1889; 15:313-372.

6. von Kölliker A. Handbuch der Gewebelehre des Menschen (6th edition), Zweiter Band: Nervensystem des
Menschen und der Thiere, Engelmann, Leipzig, 1896.

7. Golgi C. The neuron doctrine - theory and facts. Nobel Lecture, December 11, 1906.

8. Sherrington CS. The Central Nervous System. In: A Text Book of Physiology (7th edition), Part III. Edited by Foster M. Macmillan \& Co Ltd., London, 1897, p. 929.

9. Palade G, Palay SL. Electron microscope observations of interneuronal and neuromuscular synapses. Anatomical Record 1954; 118:335-336.

10. De Robertis EDP, Bennett HS. Some features of the submicroscopic morphology of synapses in frog and earthworm. J Biophys Biochem Cytol 1955; 1:47-58.

11. Palay SL. Synapses in the central nervous system. J Biophys Biochem Cytol 1956; 2:193-202.

12. Jastrow H. Electron Microscopic Atlas of cells, tissues and organs in the internet, 2011. http://www.uni-mainz. de/FB/Medizin/Anatomie/workshop/EM/EMAtlas.html

13. Eccles JC, Fatt P, Koketsu K. Cholinergic and inhibitory synapses in a pathway from motor-axon collaterals to motoneurones. J Physiol 1954; 126:524-562.

14. Eccles JC. Excitatory and inhibitory synaptic action. Ann NY Acad Sci 1959; 81:247-264.

15. Eccles JC. The ionic mechanism of postsynaptic inhibition. Nobel Lecture, December 11, 1963.

16. Palade GE. Intracellular aspects of the process of protein secretion. Nobel Lecture, December 12, 1974.

17. Katz B. On the quantal mechanism of neural transmitter release. Nobel Lecture, December 12, 1970.

18. Mashour GA. Consciousness unbound: toward a paradigm of general anesthesia. Anesthesiology 2004; 100:428-433.

19. Beck F, Eccles JC. Quantum aspects of brain activity and the role of consciousness. Proc Natl Acad Sci USA 1992; 89:11357-11361.

20. Eccles JC. Evolution of consciousness. Proc Natl Acad Sci USA 1992; 89:7320-7324.

21. Gerst JE. SNAREs and SNARE regulators in membrane fusion and exocytosis. Cell Mol Life Sci 1999; 55:707734.

22. Sutton RB, Fasshauer D, Jahn R, Brünger AT. Crystal structure of a SNARE complex involved in synaptic exocytosis at 2.4 A resolution. Nature 1998; 395: 347-353.

23. Fasshauer D, Sutton RB, Brunger AT, Jahn R. Conserved structural features of the synaptic fusion complex: SNARE proteins reclassified as Q- and R-SNAREs. Proc Natl Acad Sci USA 1998; 95: 15781-15786. 
24. Chapman ER. Synaptotagmin: a $\mathrm{Ca}^{2+}$ sensor that triggers exocytosis? Nat Rev Mol Cell Biol 2002; 3: 1-11.

25. Chapman ER, An S, Edwardson JM, Jahn R. A novel function for the second $\mathrm{C} 2$ domain of synaptotagmin. $J$ Biol Chem 1996; 271:5844-5849.

26. Rizo J, Rosenmund C. Synaptic vesicle fusion. Nat Struct Mol Biol 2008; 15:665-674.

27. Ting JT, Phillips PEM. Neurotransmitter Release. In: Wiley Encyclopedia of Chemical Biology: John Wiley \& Sons, Inc., 2008.

28. Zucker RS. Exocytosis: A molecular and physiological perspective. Neuron 1996; 17:1049-1055.

29. Wang C-T, Lu J-C, Bai J, Chang PY, Martin TFJ, Chapman ER, Jackson MB. Different domains of synaptotagmin control the choice between kiss-and-run and fullfusion. Nature 2003; 424:943-947.

30. Silver RB, Kriebel ME, Keller B, Pappas GD. Porocytosis: Secretion from small and medium-diameter vesicles and vesicle arrays without membrane fusion. $J$ Neurocy- tol 2003; 32:277-291.

31. Jena BP. Porosome: the universal secretory portal in cells. Biomed Rev 2010; 21:1-15.

32. van Swinderen B, Saifee O, Shebester L, Roberson R, Nonet ML, Crowder CM. A neomorphic syntaxin mutation blocks volatile-anesthetic action in Caenorhabditis elegans. Proc Natl Acad Sci USA 1999; 96:2479-2484.

33. van Swinderen B, Metz LB, Shebester LD, Mendel JE, Sternberg PW, Crowder CM. Go $\alpha$ regulates volatile anesthetic action in Caenorhabditis elegans. Genetics 2001; 158:643-655.

34. MacIver MB, Mikulec AA, Amagasu SM, Monroe FA. Volatile anesthetics depress glutamate transmission via presynaptic actions. Anesthesiology 1996; 85:823-834.

35. Dean C, Dresbach T. Neuroligins and neurexins: linking cell adhesion, synapse formation and cognitive function. Trends Neurosci 2006; 29:21-29.

36. Südhof, TC. Neuroligins and neurexins link synaptic function to cognitive disease. Nature 2008; 455:903-911. 